\title{
The unusual tegumental tissues of the Lunaria annua (Brassicaceae) seed: A developmental study using light and electron microscopy
}

\author{
Stefano Mosti ${ }^{\mathrm{a}}$, Cynthia Ross Friedman ${ }^{\mathrm{b}}$, Fabio Piccolin ${ }^{\mathrm{a}}$, Pietro Di Falco ${ }^{\mathrm{a}}$, Alessio Papini ${ }^{\mathrm{a}, *}$ \\ a Department of Evolutionary Biology, Università di Firenze, Via La Pira, 4, 50121 Firenze, Italy \\ b Department of Biological Sciences, Thompson Rivers University, 900 McGill Road, Kamloops, British Columbia, Canada V2C 0C8
}

\section{A R T I C L E I N F O}

Article history:

Received 23 May 2012

Accepted 10 September 2012

Keywords:

Brassicaceae

Lipids

Seed dispersal

Seed integuments

Seed anatomy

Buoyancy

\begin{abstract}
A B S T R A C T
With light, fluorescence, transmission electron, and environmental scanning electron microscopy we studied the development of the Lunaria annua L. (Brassicaceae) seeds in order to reveal basic anatomical information about the unusual tissues of these seeds. In particular the seed tegument tissues possess complex morphological aspects that are relevant to the biology and ecology of this plant. A sclerenchymatic tissue as the innermost layer of the teguments apparently offers robust protection for the embryo, yet is organized to be flexible. This tissue likely controls the passage of water from the tegumental layers towards the embryo. We report here the presence of tannins in the pre-sclerenchymatic layer of the unripe seed. The inner tegument also houses a spongy tissue with wide intercellular spaces. This tissue could impart buoyancy to the seeds, which possibly might be required for water transport. The structural features could indicate that Lunaria may have evolved in a Mediterranean environment, which is characterized by a long dry season, but with a large amount of rainfall concentrated in short periods. Probably, not only the typical enlarged and flattened fruits of Lunaria can easily float and be dispersed away from the mother plant, but also the seeds have this dispersal peculiarity after release from the silicules.
\end{abstract}

(c) 2012 Elsevier GmbH. All rights reserved.

\section{Introduction}

Lunaria L. is a genus of Brassicaceae characterized a by large membranous silicula which is oblong-elliptical to suborbicular, rounded at the base and apex and containing disc-shaped seeds (Fig. 1; see also Ball, 1993). Lunaria annua L. is a species originating from western Asia and south-eastern Europe (Pignatti, 1982), and has now naturalised in many temperate countries, where it is a popular ornamental flower (Guo et al., 2009). A biennial or perennial cruciferous plant, it has a high (35\%) oil content in its seeds. The oil, comprised of very long-chain mono-unsaturated fatty acids (e.g., nervonic acid) has been used as an industrial lubricant (Guo et al., 2009; Mastebroek and Marvin, 2000) and may have potential interest for other applications, e.g. for biofuel production like other Brassicaceae (Appelquist, 1976; Ciccarelli et al., 2010; Papini and Simeone, 2010; Papini et al., 2010a,b).

When the seed of $L$. annua is ripe, the lipids are primarily stored within the embryo, which is separated from the outside environment by the seed coat (testa), which is comprised of tegumental layers (can also be called 'integuments'). Only a limited number of studies describe the six tegumental tissues typical for L. annua seeds. Three externally positioned layers of the developing seed

\footnotetext{
* Corresponding author. Tel.: +39 0552757395

E-mail address: alpapini@unifi.it (A. Papini).
}

derive from the outer ovule tegument, while the three more internal layers originate from the inner tegument (Bouman, 1975). The most external tissue is the epidermis, the second the sub-epidermal tissue, while the third has been defined as 'palisade tissue' (Van Caeseele et al., 1982; Vaughan and Whitehouse, 1971). The fourth, fifth and sixth tissue layers of the L. annua testa correspond, respectively, to the superficial, middle (or 'spongy'), and basal tissues of the inner tegument (Bouman, 1975). The middle and basal tissues are particularly striking due to their dark appearance. Vaughan and Whitehouse (1971) called the basal tissue 'the pigmented tissue' because of its strong reactivity to Toluidine blue stain. In the ripe seed, cells of the basal tissue are dead, and were identified as sclereids by Bouman (1975). In our study, we undertook an investigation of the anatomy and ultrastructure of the tegumental tissues in L. annua throughout the embryo development until seed ripening was achieved. The ultrastructural observations of these tissues are the first of their kind for L. annua. We also examined the cytochemistry of these tissues at maturity in order to better understand the nature of these important tissues.

\section{Materials and methods}

\section{Plants}

Lunaria annua plants were grown in the Botanical Garden of the University of Florence (Italy). Unripe and later ripe fruits (the typical 


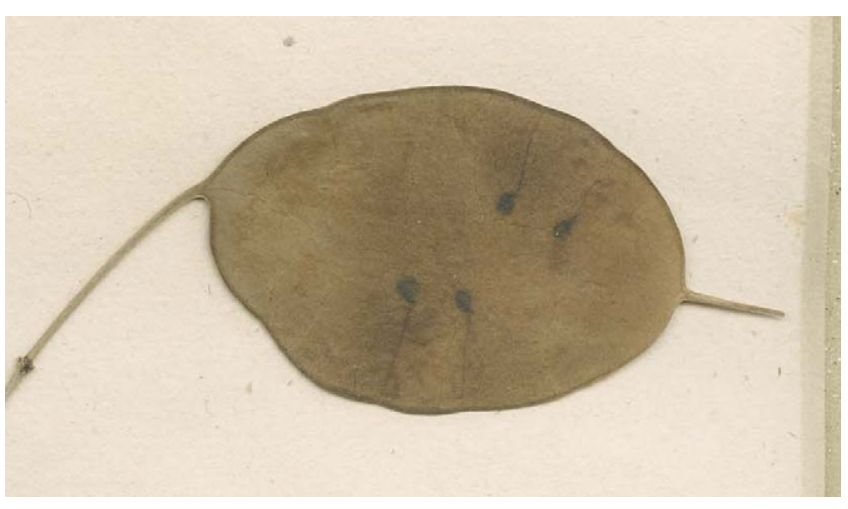

Fig. 1. A mature fruit of Lunaria annua L. (silicula) from an Herbarium sample collected at Certosa (near Florence).

enlarged and flattened siliques of Lunaria) were collected at different developmental stages recognized on the basis of the silicule dimensions: $3.5 \mathrm{~cm} \times 2.5 \mathrm{~cm} ; 4 \mathrm{~cm} \times 2.6 \mathrm{~cm} ; 4.5 \mathrm{~cm} \times 2.9 \mathrm{~cm}$ (ripe) and the seeds used for the investigations. Some of the ripe seeds were hydrated for $24 \mathrm{~h}$.

\section{Embedding process for light and electron microscopy}

Seeds at different stages of development were prefixed overnight in $1.25 \%$ glutaraldehyde at $4{ }^{\circ} \mathrm{C}$ in $0.1 \mathrm{M}$ phosphate buffer ( $\mathrm{pH}$ 6.8), and then fixed in $1 \% \mathrm{OsO}_{4}$ in the same buffer for $1 \mathrm{~h}$. After dehydration in an ethanol series and a propylene oxide step, the samples were embedded in Spurr's epoxy resin (Spurr, 1969).

\section{Sectioning and staining for light and fluorescence microscopy}

Seeds embedded in Spurr's epoxy resin were sectioned with glass knives to obtain semi thin sections $(1-5 \mu \mathrm{m})$, which were stained with Toluidine blue, $0.1 \%$, then observed and photographed with a Leitz DM RB light microscope. Seeds that were not embedded were instead sectioned with a Cryostat to generate semi-thin sections $(10-20 \mu \mathrm{m})$. Some of these seed sections were stained with $1 \%$ phloroglucinol $(\mathrm{w} / \mathrm{v})$ in $12 \% \mathrm{HCl}$ for $5 \mathrm{~min}$ and observed with a bright field light microscope for the detection of lignin (Fernandez and Heath, 1986). Another set of cryostat sections were stained with Sudan III for the detection and localization of lipids under bright field microscopy (Brundrett et al., 1991). The remainder of the Cryostat sections were stained with Fluorol Yellow 088 and viewed with a fluorescent microscope Leica DM RB Fluo in the range of 515-565 nm (green) to detect lipids (Brundrett et al., 1991). Series of images were treated with the python program ALLAMODA2.0 (Papini, 2012) to reduce noise.

\section{Transmission electron microscopy (TEM)}

Pieces of seeds embedded in Spurr's epoxy resin (Spurr, 1969) were also cut with a diamond knife to generate sections that were approximately $80 \mathrm{~nm}$ thick. These were stained with uranyl acetate (Gibbons and Grimstone, 1960) and lead citrate (Reynolds, 1963), and then examined with a Philips EM300 TEM operating at $80 \mathrm{kV}$.

\section{Environmental Scanning Electron Microscopy (ESEM)}

Seeds of $L$. annua were hand-cut with a razor blade; resulting sections $(0.5-1 \mathrm{~mm})$ were mounted on stubs. We used a Quanta 200 Environmental Scanning Electron Microscopy (ESEM, Fei Corporation, The Netherlands) operating in low-vacuum mode (the chamber pressure was kept at 1 Torr) to observe the samples and generate images by the CEME center (www.ceme.fi.cnr.it).

\section{Results}

The tegumental layers of the seed testa become clearly evident as the six distinct tissues (epidermal, sub-epidermal tissue, and palisade of the outer tegument; superficial, spongy, and basal of the inner) only when the embryo has progressed into the early heart stage (Fig. 2B). Seeds at this stage possess a free-nuclear endosperm with a large central vacuole and remnant nucellus (Fig. 2A). Following is a description of the tissue regions of the tegumental layers surrounding a seed with a heart stage embryo, with an emphasis on the ultrastructure. The tissues are described from the outside towards the internal part of the seed (occupied by the cavity housing the endosperm and the developing embryo).

\section{Tegumental tissues at the heart stage}

\section{Epidermal tissue (outer tegument)}

The epidermal tissue, the most external tissue, is monolayered and composed of cells with a roundish shape (Fig. 2B). These cells have thick external tangential walls with a noteworthy cutin layer, identified with TEM to be a strongly electron-dense coat (Fig. 2C). The nuclei are located at the periphery of the cells (Fig. 2D). Relatively large vacuoles occupy a central position, while other smaller vacuoles along with large globular starch containing amyloplasts could be observed in the peripheral cytoplasm (Fig. 2C).

\section{Sub-epidermal tissue (outer tegument)}

The sub-epidermal tissue shows two to many cell layers (Fig. 2B). The cells are smaller and more flattened than those of the epidermal layer. The vacuoles in sub-epidermal cells occupy a smaller part of the cell volume as compared with cells in the epidermal layer (Fig. 2E). These sub-epidermal cells also contain prominent amyloplasts with starch (Fig. 2E). A main feature of the sub-epidermal cell cytoplasm is the presence of long rough endoplasmic reticulum (RER) cisternae. This RER seems to be continuous with large vesicles that contain densely granular materials of medium electron density, and the membranes of these vesicles appear to be covered with ribosomes (Fig. $2 \mathrm{~F}$ ).

Bundles of conductive tissue are present in the sub-epidermal region. Conductive elements (tracheid-like cells with annular thickenings) are also visible in islands of tissues observed close to the hilum-micropylar zone of the seed (Fig. 3A). Cells of these islands are smaller, have a more electron-dense cytoplasm, and are less vacuolated than the surrounding cells.

\section{Palisade layer (outer tegument)}

The palisade layer is primarily a monolayered tissue, and forms the basal layer of the outer tegument (Fig. 2B). The cells composing this tissue are normally radially elongated and possess strongly thickened inner tangential and basal radial walls (Fig. 3B). The nucleus of these cells is spherical and mainly euchromatic, but contains some condensed heterochromatin. A single nucleolus is typically visible (Fig. 3B). The cytoplasmic matrix has a medium electron density, with ribosomes either free or associated in polysomes (Fig. 3C), and typically contains one or two large vacuoles and some smaller vacuoles (Fig. 3B). Mature or developing amyloplasts are also present in the cytoplasm, each containing one to two starch grains (Fig. 3B). Some amyloplasts seem to be engulfed in vacuoles (Fig. 3B). Close to the walls, dictyosomes produce vesicles, some of which can be seen fusing with the plasma membrane (Fig. 3C). Structures with a paracrystalline appearance are frequently observed (Fig. 3D). When viewed in longitudinal 

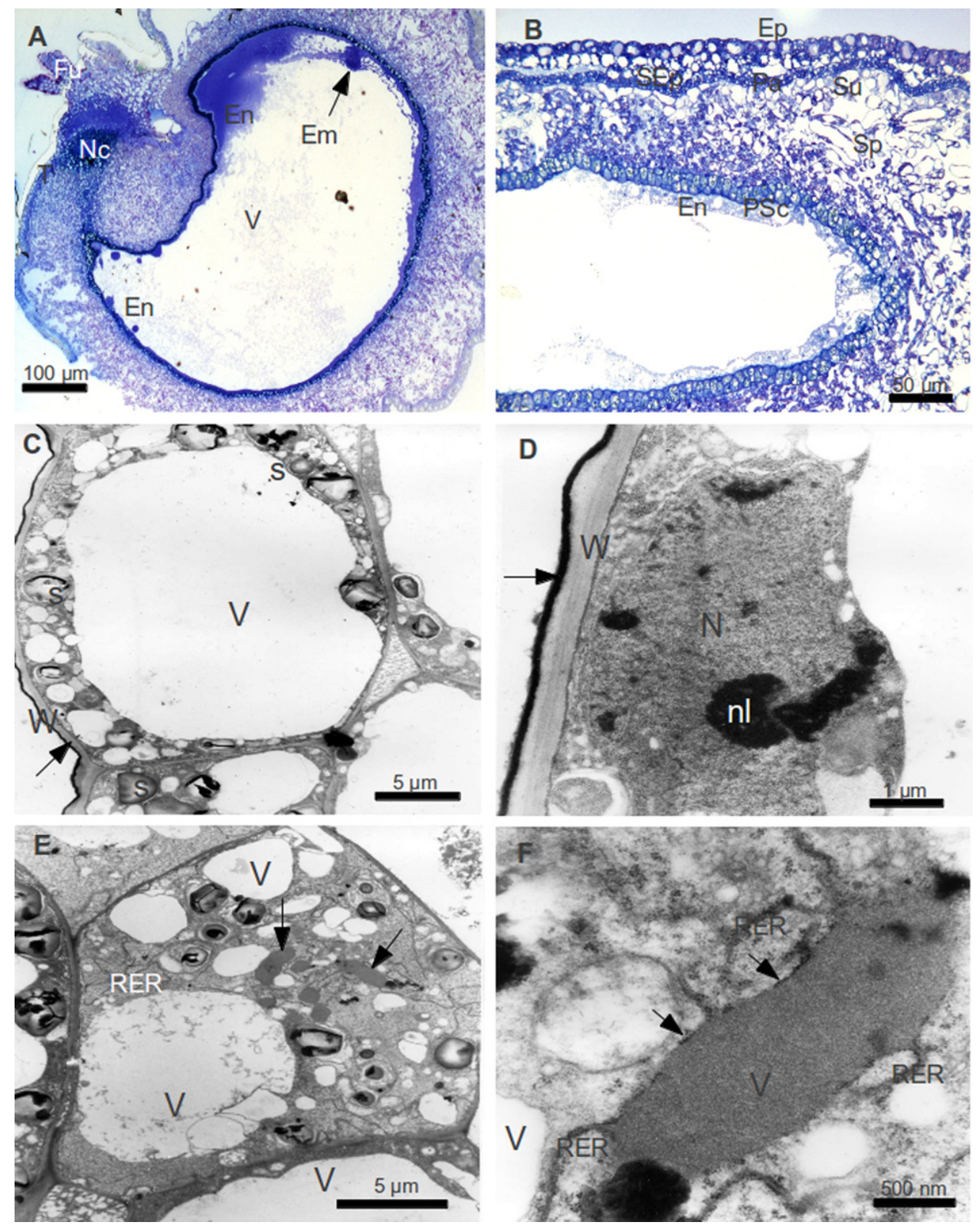

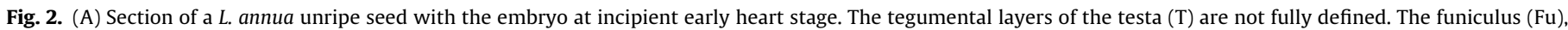

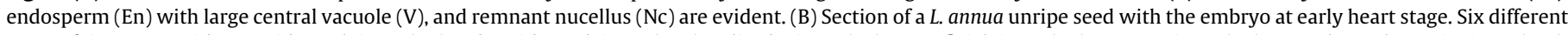

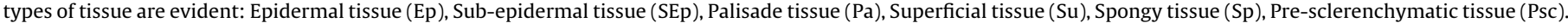

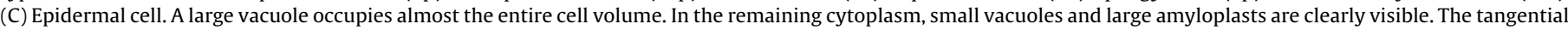

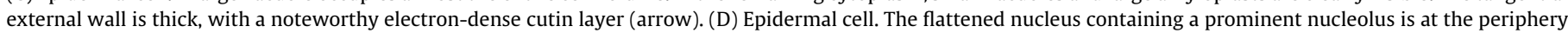

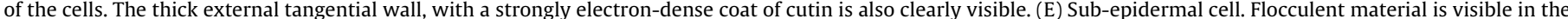

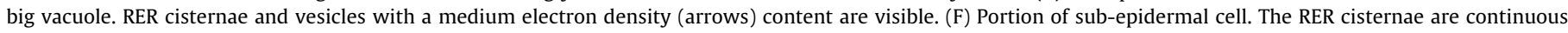

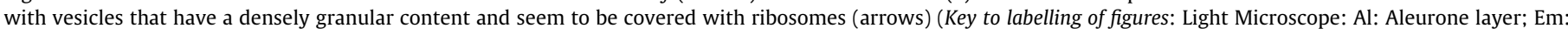

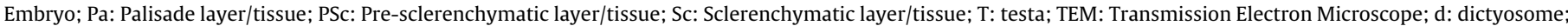

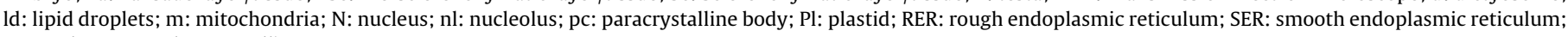
S: starch; V: vacuole; W: wall).

section these paracrystalline bodies take on the appearance of filament bundles. Individual filaments are $30 \mathrm{~nm}$ in diameter.

\section{Superficial tissue (inner tegument)}

This tissue forms the outermost covering of the inner tegument, and is a one to three-cell-layered tissue found between the palisade layer of the outer tegument and the spongy tissue of the inner tegument (Fig. 2B). The cells constituting the tissue differ in both shape and dimension and could be isodiametric, radially elongated, or tangentially elongated (Fig. 3E). The number of layers is variable as well, ranging from one (the most frequent condition) to two or three (Figs. 2B and 3E). Sometimes even the single cell layer was incomplete. The cells in this tissue have large vacuoles as well as some smaller ones containing granular matter of medium electron density and amyloplasts (Fig. 3F).

\section{Spongy tissue (inner tegument)}

This is the fifth tissue from the outside toward the internal chamber, and is a multilayered tissue. It shows different morphologies depending on the point of observation: in the lateral area of 

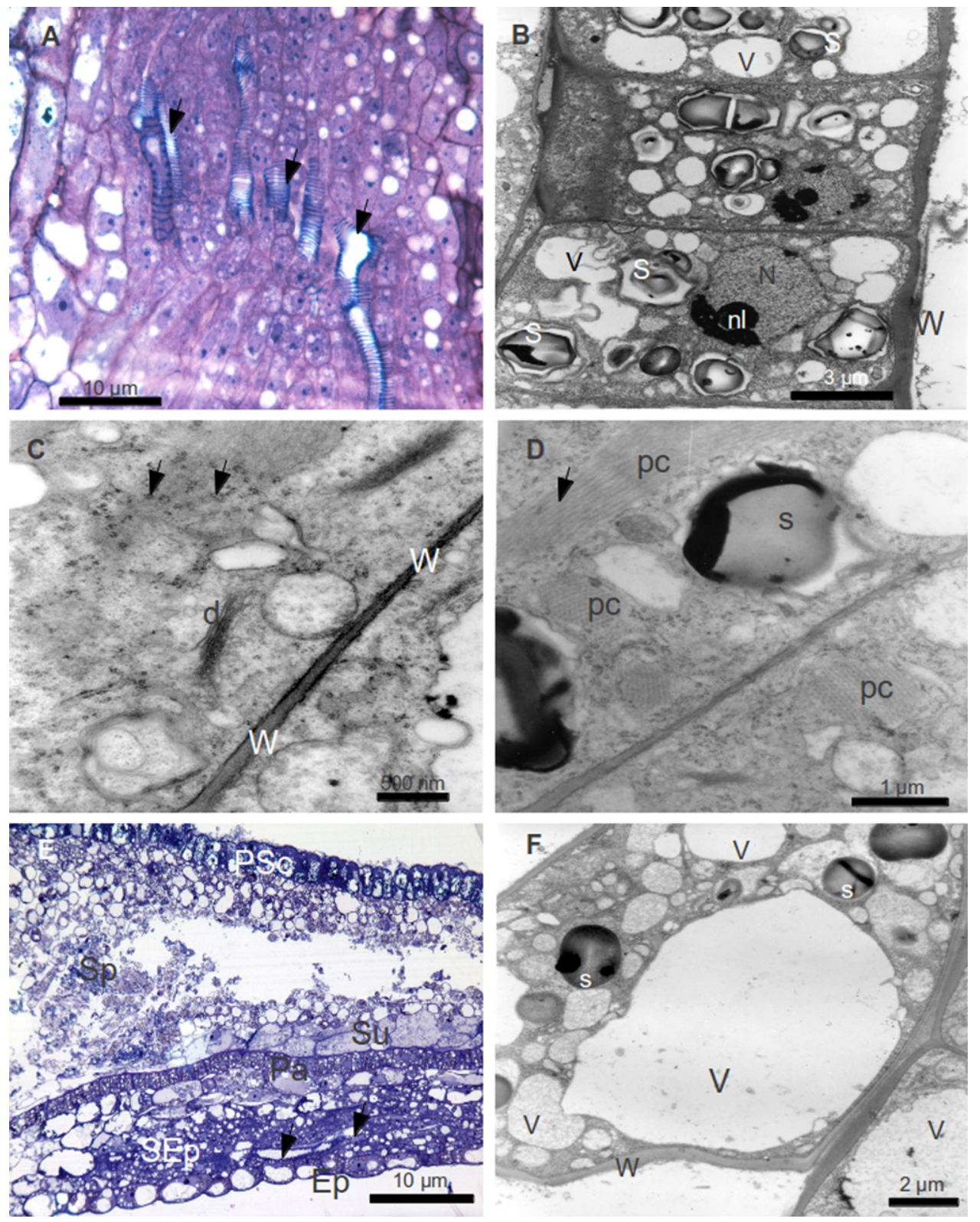

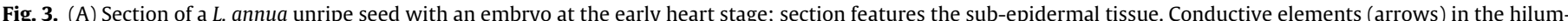

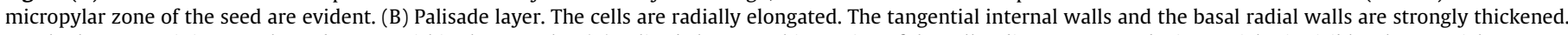

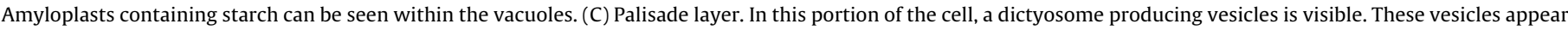

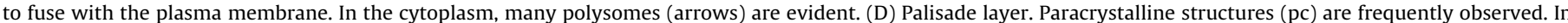

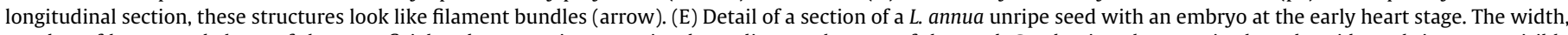

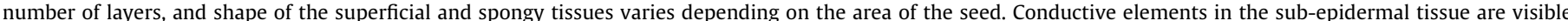

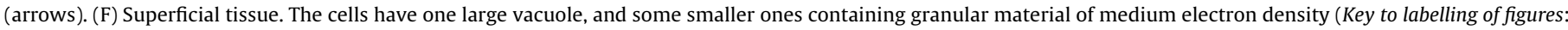
see legend of Fig. 2).

the seed, this tissue appears quite compact with reduced intercellular spaces (Fig. 2B). The cells in this area appear to be roundish, ovoid, or quite elongated. Conversely, in the dorsal area of the seed, the volume of this tissue increases remarkably, and the intercellular spaces appear as being dilated (Fig. 2B). The cells of the dorsal area are elongated or at least elliptic (Fig. 4A). While the entire spongy tissue is multilayered, the number of layers was difficult to determine, particularly in the dorsal area, where the intercellular spaces are enlarged. Where the cells remain in contact with each other, plasmodesmata are evident at the adhesion points (Fig. 4B). Ultrastructurally, the cells of this tissue are similar. They typically possess a main (central) vacuole with an electron-transparent content as well as smaller vacuoles (Fig. $4 \mathrm{~A}$ ). The nucleus most often has a peripheral position and a flattened or irregular shape. It is typically almost completely euchromatic with a prominent single nucleolus (Fig. 4C). The remaining cytoplasm possesses a poorly electron-dense matrix and relatively large amyloplasts together with long RER cisternae disposed in parallel arrays (Fig. 4B and D). The walls have a fibrillar appearance (Fig. 4D).

\section{Basal or 'pre-sclerenchymatic' tissue (inner tegument)}

The basal tissue is the most internal tissue among those forming the teguments of L. annua. As it later becomes sclerified, we have decided to call this tissue the 'pre-sclerenchymatic' tissue when it is observed at this stage of development. The pre-sclerenchymatic tissue covers the internal chamber where the embryo will develop, 


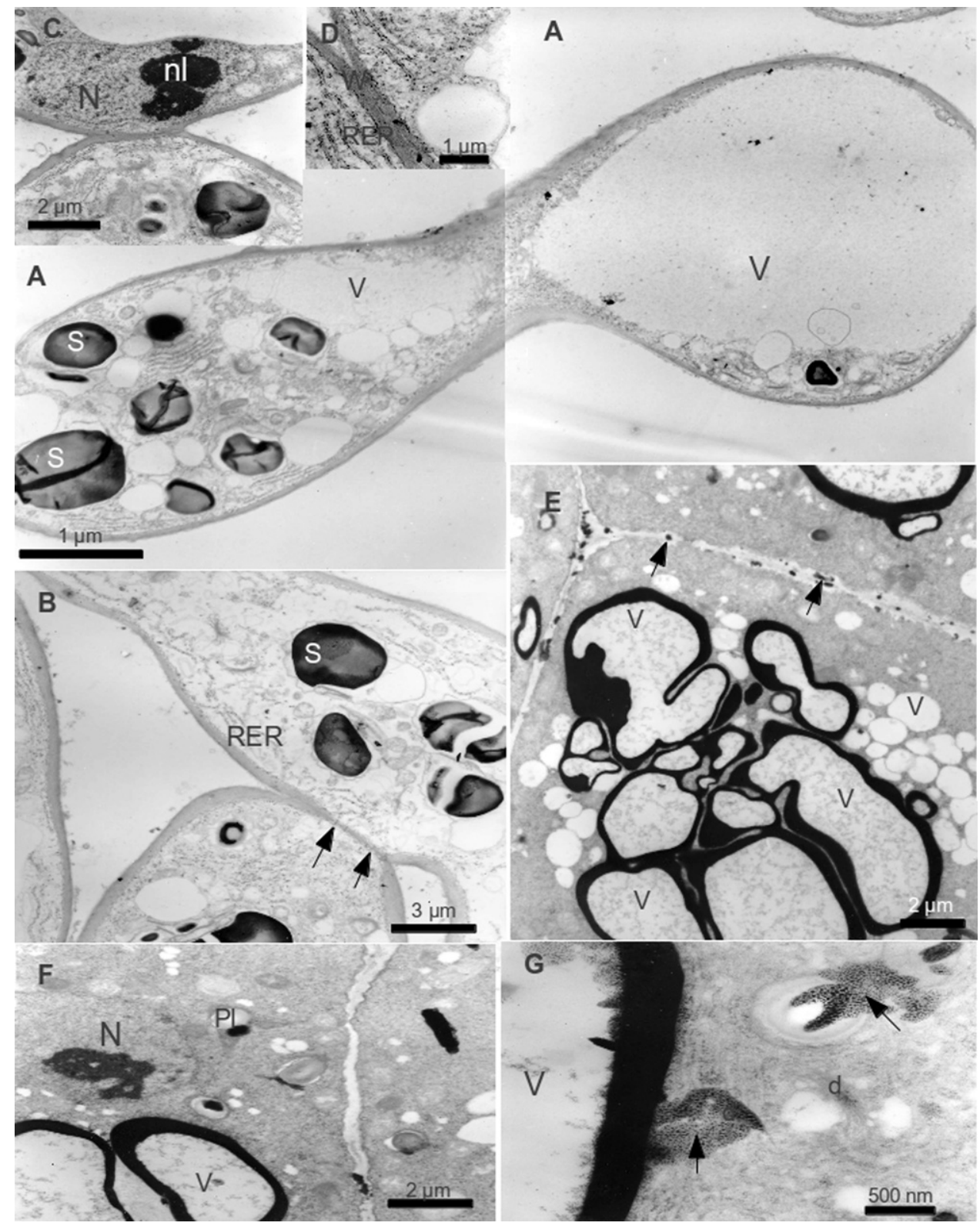

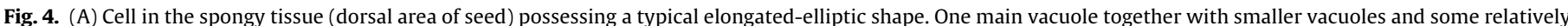

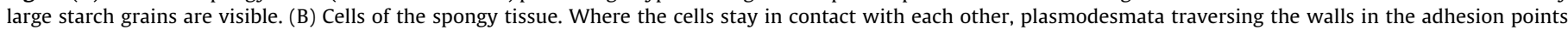

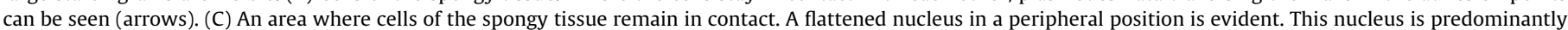

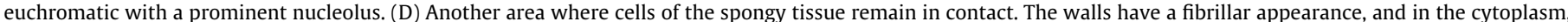

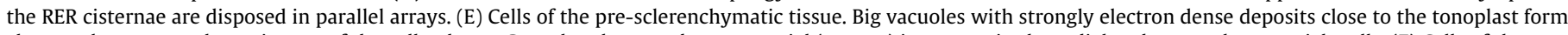

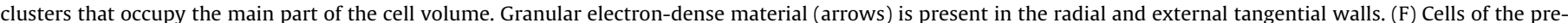

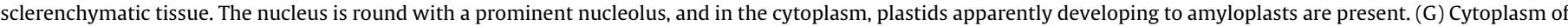

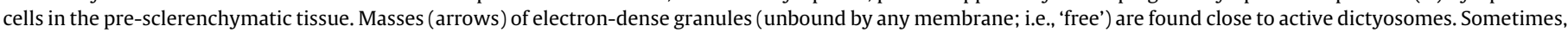
such masses were observed in the vicinity of the big vacuole tonoplasts (Key to labelling of figures: see legend of Fig. 2).

and is in direct contact with the endosperm; cells in contact with the endosperm have convex walls. The tissue appears to be constituted by one cell layer at the micropylar pole, and multiple cell layers at the chalazal pole (Figs. 2B and 3E).

Ultrastructurally, big vacuoles in clusters occupy the main part of the cellular volume (Fig. 4E). Within these vacuoles, appressed to the tonoplast, continuous deposits of strongly electron-dense and compact material are evident (Fig. 4E). Sometimes these deposits extend towards the center of the vacuoles, but as a more rarefied and apparently floccular material (Fig. 4E and F). Smaller vacuoles occupy a more peripheral position, are weakly electrondense, and lack the electron-dense deposits seen in the larger vacuoles (Fig. 4E). Masses of electron-dense granules can be seen free in the cytoplasm, close to active dictyosomes that are producing vesicles (Fig. 4G). These electron-dense cytoplasmic masses can also be seen in the vicinity of the tonoplast of the big vacuoles that contain the electron-dense material (Fig. 4G). Granular electron-dense material is also present outside the plasma membrane in the areas of the radial and external tangential walls, and can be seen in the walls themselves, apparently within the middle lamella (Fig. 4E). Nuclei are typically round and contain a prominent nucleolus; the cytoplasm possesses a dense matrix where plastids (apparently developing into amyloplasts) are evident (Fig. 4F). 

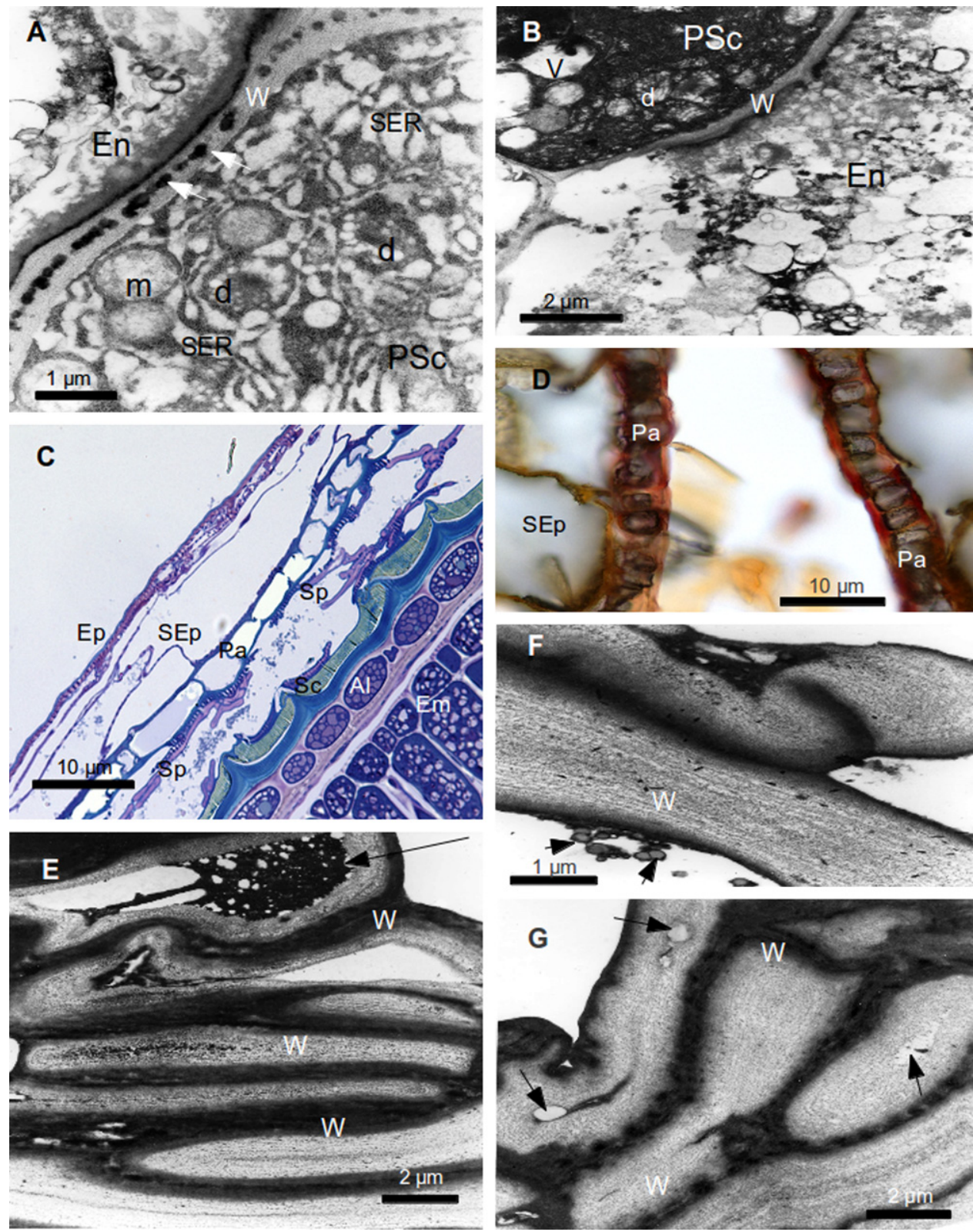

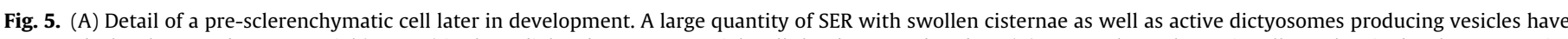

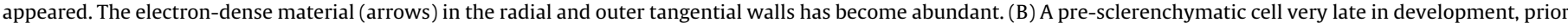

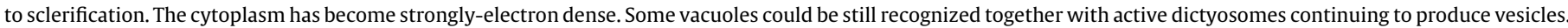

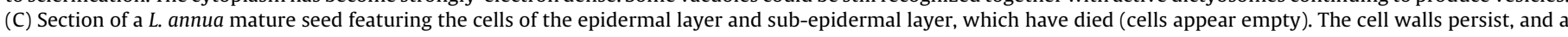

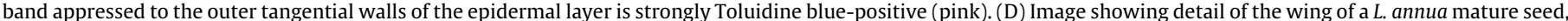

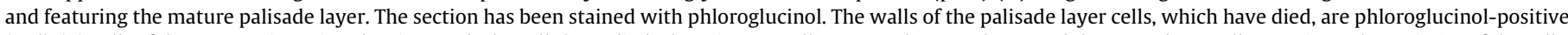

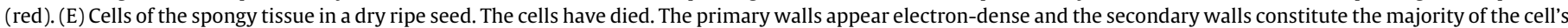

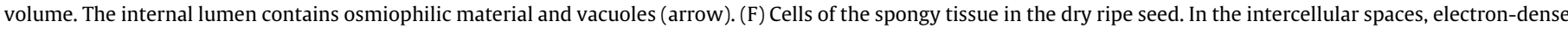

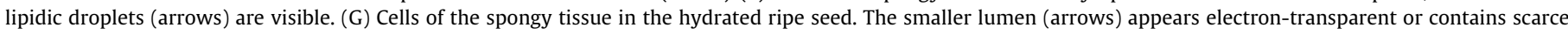

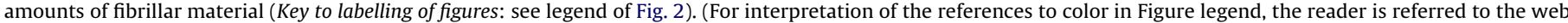
version of the article.)

As development progresses, the cells belonging to the presclerenchymatic tissue become more electron-dense, and a large quantity of SER with swollen cisternae appears (Fig. 5A). The dictyosomes become very active, producing small vesicles (Fig. 5A). The electron dense material in the radial and outer tangential walls increases in volume (Fig. 5A). Finally, the cytoplasm of the pre-sclerenchymatic cells becomes strongly electron-dense, obliterating much of the cellular ultrastructure (Fig. 5B). Nevertheless, some vacuoles could still be recognized together with active dictyosomes continuing to produce vesicles.

\section{Tissues in the teguments of the ripe seed of $L$. annua (all tissues are now dead)}

\section{Outer tegument}

In the mature seed, cells of the epidermal layer have died, as the cells appear empty. The cell walls persist, though, with the outer tangential ones being particularly thick: a band appressed to the outer tangential walls is strongly Toluidine blue-positive (pink) (Fig. 5C). Like the epidermal layer, the one to three layers of the sub-epidermal tissue are also dead at maturity (Fig. 5C). These 
cells remain irregularly shaped, are somewhat flattened, and have slightly thickened walls. The basal layer of the inner tegument, the palisade layer, now forms a continuous band (Fig. 5C): these cells have died as well. They have a prismatic shape, and possess thickened, phloroglucinol-positive (thus lignin-containing) walls, particularly in the areas where the seed has formed outgrowths or 'wings' (Fig. 5D).

\section{Inner tegument}

At maturity, the superficial tissue, which was the outermost tissue of the inner (in)tegument, is no longer distinguishable as a discrete tissue, as it has apparently merged with the spongy tissue. Cells of the spongy layer remain loosely connected to each other and possess large intercellular spaces (Fig. 5C). The ultrastructure of these cells indicates that they too are dead at maturity, constituted mainly of wall material (Fig. 5E). The primary walls are electrondense and formed by compact material, while the secondary walls comprise the majority of the cellular volume. These secondary cell walls are composed of loose fibrillar material among which some electron-dense granular material is visible (Fig. 5E and F). Electrondense droplets, likely comprised of lipids, are sometimes evident within the wide intercellular spaces (Fig. 5F).

While cell wall material fills the majority of a given cell's volume in the spongy tissue, these cells still possess an internal lumen. In dry seeds, the lumen is apparently occupied by osmiophilic material with embedded vacuoles (Fig. 5E). In hydrated seeds, however, the lumen is smaller than in the dry seed, and is sometimes not even visible. The lumen appears either fully electron-transparent or may contain scarce amounts of fibrillar material, which is found predominantly along the walls (Fig. 5G).

When stained with Fluorol Yellow (Fig. 6A), the spongy tissue of the mature dry seed shows only condensed clusters of lipid grains lining the walls, and has no staining reaction at all when treated with Sudan III (Fig. 6B). On the contrary, the spongy tissue of the hydrated seed stained with Fluorol Yellow (Fig. 6C), and Sudan III (Fig. 6D) becomes diffusely positive for the presence of lipids, as does the embryo and the aleurone layer.

At maturity, the basalmost tissue, formerly the presclerenchymatic tissue, has become fully sclerified, and can now be called the 'sclerenchymatic tissue' (Fig. 5C). Its cells share a boundary with the aleurone layer of the endosperm. Cells of the sclerenchymatic tissue have very thickened radial and inner tangential walls, giving these cells a ' $U$ '-shaped configuration in which they lack an obvious outer tangential wall. These cells are dead at maturity but not empty, since an amorphous and compact dense material is visible (Fig. 5C). The ESEM images (Fig. 6E) show that the material in these dead cells comprises solid blocks of more or less regular prismatic shape (Figs. $5 \mathrm{C}$ and $6 \mathrm{E}$ ). These solid blocks appear to be formed by apposition of bricklike deposits (Fig. 6F). Small spherical electron-dense masses are often evident in the cavity between the sclerenchymatic cell walls and the internal blocks of these cells (Fig. 6F). Both the cell walls and the solid internal blocks of the sclerenchymatic layer are phloroglucinolpositive for lignins, with the blocks staining particularly intensely (Fig. 6G). The bases of the inner tangential walls in contact with the aleurone layer show a widespread porosity; the most thickened of these walls appear stratified (Fig. 6H).

\section{Discussion}

\section{Development in the outer tegumental tissues}

\section{Epidermal layer and sub-epidermal tissue}

One of the obvious features of the developing epidermal layer in $L$. annua was the copious amount of amyloplasts. The presence of starch granules in external seed layers has been linked to the formation of mucilages (Harris, 1991), hydrophilic polysaccharides produced in specific tissues of seeds in various species of angiosperms (Western et al., 2000) and particularly in Brassicaceae (Vaughan and Whitehouse, 1971). However, we did not observe any mucilage production by the epidermal layer of $L$. annua nor pre-secretory cytoplasmic mucilage storage as described by Windsor et al. (2000) for Arabidopsis. The starch may be instead used in the thickening of the epidermal cell walls.

The sub-epidermal tissue possessed cells also containing numerous and large amyloplasts, again likely to be used in wall thickening. The tracheid-like conductive elements present in the conductive tissue bundles of this tissue may be tracheoids, vascular elements commonly found at the end of the leaf veins (Gonzalez and Lopez, 2010) and documented in seeds wings of Bignoniaceae (Lersten et al., 2002). Lunaria is the only genus of Brassicaceae known to have an extensive tegumentary seed vascularization (Bouman, 1975). In leaves, these tracheoids function in water storage, air storage, and mechanical support (Gonzalez and Lopez, 2010), and in the seed, they may have roles in short distance water transport (Fahn, 1990). Ultrastructurally, the most interesting aspect of the sub-epidermal tissue was the presence of long RER tracts ending in vacuoles of medium electron density. The contents of these RER cisternae and associated vacuoles were similarly granular and electron-dense, probably of a proteinic nature. Such proteins may be enzymes involved in the developmental processes and in the autophagic activity in this tissue and possibly adjacent tissues, particularly the palisade tissue (see next section).

\section{Palisade layer}

In the palisade layer, the dictyosomes and secretory vesicles were likely functioning to transport cellulose and pectic substances necessary for the wall thickening processes, as suggested also by Van Caeseele et al. (1982) in Brassica campestris. The presence of starch granules would represent a carbohydrate source for these processes.

The paracrystalline structures observed in the cells of this tissue are difficult to positively identify without immunocytochemistry, but could be peroxisomes or glyoxysomes, organelles that play a role in breakdown of very long chain fatty acids through betaoxidation (Michels et al., 2005). Van Caeseele et al. (1982) saw similar structures in B. campestris, calling them 'tubular paracrystalline structures', but did not attribute any particular function to them. However, when viewed in longitudinal section, these paracrystalline structures took on the appearance of filament bundles. What we putatively call 'peroxisomes' might be filament bundles in cross section. If the paracrystalline bodies are truly the filament bundles, they might be necessary to give more rigidity to these cells while they are still alive. The diameter of these filaments ( $30 \mathrm{~nm}$ ) corresponds more closely to the dimension of microtubules (about $25 \mathrm{~nm}$ ), but without their typical morphology.

The presence of amyloplasts within the vacuoles of palisade layer cells signals the onset of autophagy and hence the later developmental stages, as was similarly observed in B. campestris (Van Caeseele et al., 1982). The autophagic processes are probably preliminary to a final programmed cell death (PCD) of these cells at maturity. In Brassica napus, the palisade layer is the main supporting tissue in the mature seed (Iwanoska et al., 1994). The dead cells of the palisade layer remaining in the mature seed of L. annua do not appear to have the same important supporting function, except in the "wing" zone, where the walls appeared lignified (phloroglucinol-positive). These lignified regions might also function to block water absorption, enabling seed buoyancy. Other lignified tissues in seeds, such as the sclerenchymatic parenchyma below the epidermis in Acacia (Venier et al., 2012), are believed 

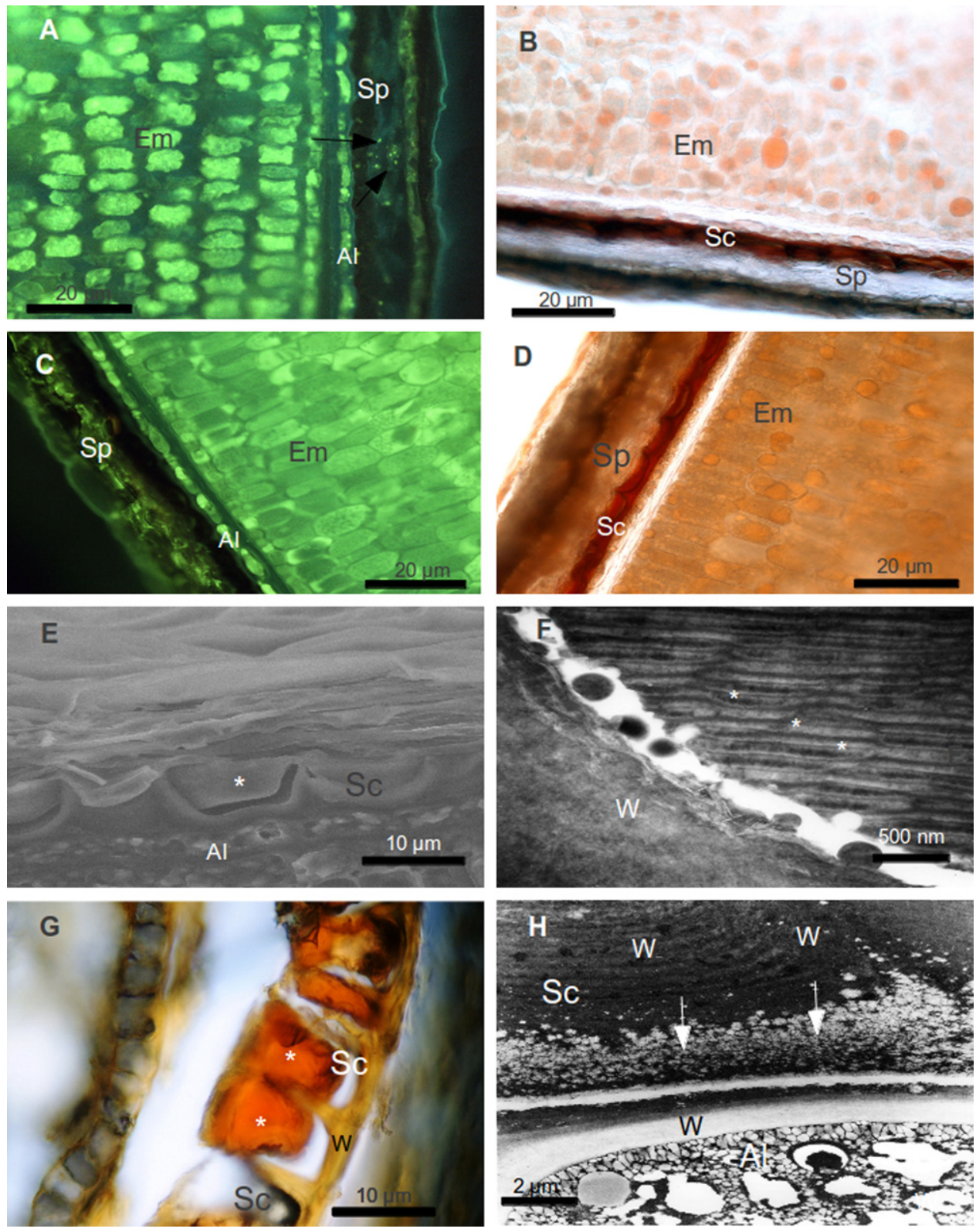

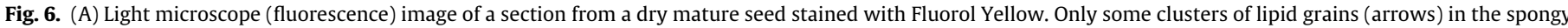

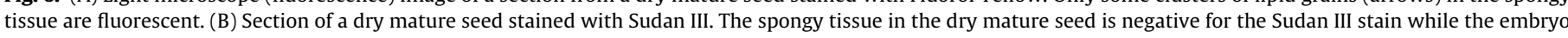

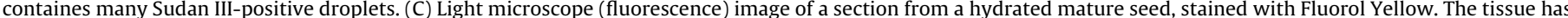

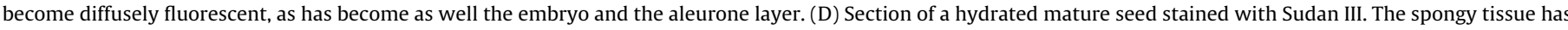

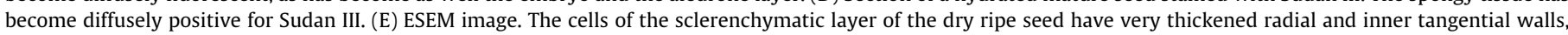

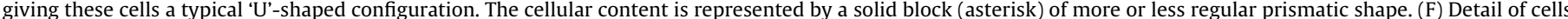

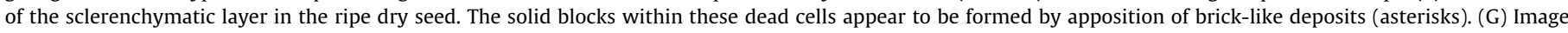

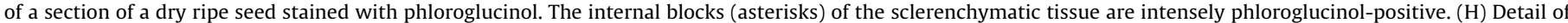

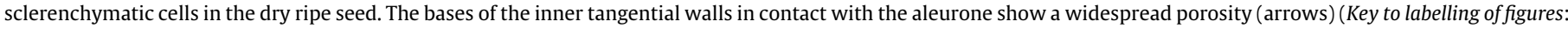
see legend of Fig. 2).

to control the water flux from outside the seed. In this case, such control could also govern seed dormancy.

\section{Development in the inner tegumental tissues}

\section{Superficial and spongy tissues}

The superficial and spongy tissue layers, strictly interconnected to one another, merge into one tissue at seed maturity. The increase in seed dimension occurs following both the dilation of the embryo chamber and the growth of the spongy tissue, with some of the volume increase attributable to the enlargement of the intercellular spaces. The symplastic contacts are nevertheless maintained as long as the cells remain viable, probably to maintain developmental synchronicity.

As the spongy tissue approaches maturity, the walls distend and the central vacuole in each cell increases in volume. The numerous smaller vacuoles that also appear are probably related to autolytic processes, which are particularly active against the amyloplasts. Therefore, the starch in amylopasts of the younger spongy tissue is likely needed to provide raw material for the wall expansion. The 
many ribosomes, both free and associated within the ER, are likely involved in producing lytic enzymes. The dead cells often showed traces of partially lysed, osmiophilic cytoplasm and nuclei, hallmarks of PCD in plants (Brighigna et al., 2006; Papini et al., 1999, 2010c, 2011). At maturity, these dead cells are characterized by their walls, which possess a loose and filamentous matrix. While porous tissues are rare in plants, Cycas seeds possess a spongy tissue that initially imparts buoyancy to the seeds to enable their dispersal in sea water, while the thick, waxy and resinous epidermis repels water (Dehgan and Yuen, 1983). Species of Cycas that lack a spongy tissue do not have buoyant seeds (Dehgan and Yuen, 1983). We suggest that the spongy tissue of Lunaria allows seed buoyancy in this taxon, as the epidermis and/or the palisade layer could block water from entering the porous regions. Throughout development and even at maturity, when the seed is dry, clusters of deposits in the intercellular spaces and lining the cell walls of the spongy tissue are Fluorol Yellow positive, indicating that they are lipids. However, these discrete droplets tend to disappear when the seed undergoes hydration, as the Fluorol Yellow staining becomes more diffuse and evident in the walls themselves, and the walls also become diffusely Sudan III positive. The diffuse positive reaction to both Fluorol Yellow and Sudan III post-hydration indicates that the lipid droplets break up, releasing their contents, which in turn become more readily accessed by the stains. These lipids might protect the cells against mechanical damage due to friction between the walls of the swelling cells.

\section{Pre-sclerenchymatic tissue/sclerenchymatic tissue}

The cells of the pre-sclerenchymatic tissue have large electrondense masses in their vacuoles. Such masses can be interpreted as phenolic compounds, probably tannins, as their ultrastructure is morphologically very similar to that described for many plants. Analogous descriptions have been given for the phenolics in the cortical cells of Reaumuria palestina (Ginzburg, 1967), in the endoderm of Gossypium hirsutum and Musa acuminata (Mueller and Greenwood, 1978), in mother tannin cells of Sambucus racemosa (Zobel, 1985), in the coenocytes of the same species (Zobel, 1986), in the root cap cells of Brassica napus (Zobel, 1989) and in the nectaries of Selenicereus grandiflorus, where phenols were detected with GC/MS analysis (Mosti et al., 2001).

As in the coenocytes of Sambucus racemosa (Zobel, 1986), the central vacuoles containing the electron-dense masses in the presclerenchymatic tissue of Lunaria appear to grow as a result of fusion with other smaller vacuoles. The vesicles responsible for the primary tannin accumulation may derive in part from ER cisternae, as suggested by Zobel (1986). However in L. annua we noted that also large dictyosome vesicles containing droplets of electrondense material apparently fuse with the tonoplast of the vacuoles. A dictyosome origin of tannin-containing vacuoles was first proposed by Juhash et al. (1970) in Cornus. Zobel (1985) also observed vesicles leaving the proximal face of dictyosomes in the mother tannin cells of Sambucus. As proposed for root endoderm of Gossypium and Musa (Mueller and Greenwood, 1978), the accumulation of tannins in the pre-sclerenchymatic layer of Lunaria could protect against pathogens (Kraus et al., 2003). Condensed tannins within vacuoles could also play a role in seed dormancy and germination as is the case with Arabidopsis (Debeaujon et al., 2001).When the presclerenchymatic tissue is in the later stages of its development the cytoplasm becomes more osmiophilic, showing signs of degeneration. Such modifications appear related to the lignification of some of the cytoplasmic components, eventually leading to the formation of solid phloroglucinol-positive blocks at maturity (as shown in ESEM images).

\section{Conclusions}

The tissues of the teguments of L. annua, both when unripe and at maturity, possess complex morphological aspects related eventually to the plant's biology and ecology. All tissues of the testa are dead at maturity, potentially creating a relatively lighter seed. The spongy tissue could be interpreted as an adaptation of the seed to increase buoyancy and floatation capability for transport in water during the rainy season. The features of this spongy tissue indicate that Lunaria is adapted to and thus may have evolved in a Mediterranean environment, which is characterized by a large amount of rainfall concentrated in short periods. Such concentrated rainfall reactivates dried streams along which the individuals of $L$. annua regularly grow, and where the typical enlarged and flattened fruits of Lunaria could easily float and be dispersed away from the mother plant, while the seeds become removed from the replum during this transport. The mature sclerenchymatic layer represents a robust layer of protection for the embryo in addition to that provided by the more external tegumental layers. The sclerenchymatic layer, being thickened, is likely elastic due to its articulated structure. The elasticity would allow the embryo to swell during hydration without breaking the protective tissue, at least at the beginning of its swelling phase.

\section{Acknowledgements}

We thank the Cassa di Risparmio di Pistoia and Pescia for the financing of the PISTOLIO project, which allowed us to investigate seed development in some members of the Brassicaceae.

\section{References}

Appelquist, L.A., 1976. Lipids in the Cruciferae. In: Vaughan, J.G., Macleod, A.J., Jones, B.M.H. (Eds.), The Biology and Chemistry of the Cruciferae. Academic Press, London, pp. 221-278.

Ball, P.W., 1993. Flora Europaea. In: Tutin, T.G., et al. (Eds.), 1 Psilotaceae to Platanaceae., 2nd ed. Cambridge University Press, Cambridge, p. 358.

Bouman, F., 1975. Integument initiation and testa development in some Cruciferae. Bot. J. Linn. Soc. 70, 213-229.

Brighigna, L., Milocani, E., Papini, A., Vesprini, J.L., 2006. Programmed cell death in the nucellus of Tillandsia (Bromeliaceae). Caryologia 59, 334-339.

Brundrett, M.C., Kendrick, B., Peterson, C.A., 1991. Efficient lipid staining in plant material with Sudan red 7B or Fluorol yellow 088 in polyethylene glycol glycerol. Biotech. Histochem. 66, 111-116.

Ciccarelli, D., Balestri, M., Pagni, A.M., Forino, L.M.C., 2010. Morpho-functional adaptations in Cakile maritima Scop. subsp. maritima: comparation of two different morphological types. Caryologia 63, 411-421.

Debeaujon, I., Peeters, A.J.M., Léon-Kloosterziel, K.M., Koornneef, M., 2001. The TRANSPARENT TESTA12 gene of Arabidopsis encodes a multidrug secondary transporter-like protein required for flavonoid sequestration in vacuoles of the seed coat endothelium. Plant Cell 13, 853-871.

Dehgan, B., Yuen, K.K.H., 1983. Seed morphology in relation to dispersal, evolution and propagation of Cycas L. Bot. Gaz. 144, 412-418.

Fahn, A., 1990. Plant Anatomy, 4th ed. Pergamon Press, Oxford.

Ginzburg, C., 1967. The relation of tannins to the differentiation of the root tissues in Reaumuria palestina. Bot. Gaz. 128, 1-10.

Fernandez, M.R., Heath, M.C., 1986. Cytological responses induced by five phytopathogenic fungi in a nonhost plant, Phaseolus vulgaris. III. Cytologically detectable responses. Can. J. Bot. 67, 676-686.

Gibbons, I.R., Grimstone, A.V., 1960. On the flagellar structure in certain flagellates. J. Biophys. Biochem. Cytol. 7, 697-716.

Gonzalez, A.M., Lopez, M.G., 2010. Development and morphology of the gynoecium and nutlet in two South-American Bulbostylis (Cyperaceae) species. Flora 205, 211-220.

Guo, Y., et al., 2009. Increase in nervonic acid content in transformed yeast and transgenic plants by introduction of a Lunaria annua L., 3-ketoacyl-CoA synthase (KCS) gene. Plant. Mol. Biol. 69, 565-575.

Harris, W.M., 1991. Seed coat development in radish (Raphanus sativus L.). Phytomorphology 41, 341-349.

Iwanoska, A., Tykarska, T., Kuras, M., Zobel, A.M., 1994. Localization of phenolic compounds in the covering tissues of the embryo of Brassica napus (L.) during different stages of embryogenesis and seed maturation. Ann. Bot. 74, 313-320.

Juhash, G.D., Danos, B., Rakovan, N., 1970. Licht- und elektronenmikroskopische Untersuchungen gerbstoffhaltiger Zellen in den reproduktiven Organen der Cornus-Arten. Annal. Univ. Scient. Budapestinensis de Rolando Eötvös nominatae Sect. Biol. 12, 157-161. 
G Model

FLORA-50645; No. of Pages 10

10

S. Mosti et al. / Flora $x x x$ (2012) $x x x-x x x$

Kraus, T.E.C., Dahlgren, R.A., Zasoski, R.J., 2003. Tannins in nutrient dynamics of forest ecosystems - a review. Plant Soil 256, 41-66.

Lersten, N.R., Krueger, L., Curtis, J.D., 2002. Tracheoid variation among Bignoniaceae seed wings, with emphasis on Campsis radicans. Int. J. Plant Sci. 163, 369-378.

Mastebroek, H.D., Marvin, H.J.P., 2000. Breeding prospects of Lunaria annua L. Ind. Crops Prod. 11 (2-3), 139-143.

Michels, P.A., Moyersoen, J., Krazy, H., Galland, N., Herman, M., Hannaert, V., 2005. Peroxisomes, glyoxysomes and glycosomes (review). Mol. Membr. Biol. 22, 133-145.

Mosti, S., Papini, A., Andalo, C., Brighigna, L., 2001. Ultrastructural aspects of the hypanthial epithelium of Selenicereus grandiflorus (L.) Britton \& Rose (Cactaceae). Flora 196, 194-203.

Mueller, W.C., Greenwood, A.D., 1978. The ultrastructure of phenolic-storing cells fixed with caffeine. J. Exp. Bot. 29, 757-764.

Papini, A., 2012. A new algorithm to reduce noise in microscopy images implemented with a simple program in Python. Microsc. Res. Techn. 75, 334-342.

Papini, A., Simeone, M.C., 2010. Forest resources for second generation biofuel production. Scand J. Forest Res. 25 (Suppl. 8), 126-133.

Papini, A., Mosti, S., Brighigna, L., 1999. Programmed cell death events in the tapetum development of Angiosperms. Protoplasma 207, 213-221.

Papini, A., Mosti, S., Lió, P., Haider, S., 2010a. BIOLIP, a biotechnology-oriented database of oil content in plants, algae, fungi and cyanobacteria. J. Biotechnol. 150 (Suppl. 1), 204-205.

Papini, A., Mosti, S., Tani, G., Di Falco, P., Lazzeri, L., Lewke Bandara, N., 2010b. Ultrastructural aspects of the embryo and different endosperm compartments, in Eruca sativa Hill cv, Nemat (Brassicaceae) during heart and torpedo stages. Caryologia 63, 197-210.

Papini, A., Tani, G., Di Falco, P., Brighigna, L., 2010c. The ultrastructure of the development of Tillandsia (Bromeliaceae) trichome. Flora 205, 94-100.
Papini, A., Mosti, S., Milocani, E., Tani, G., Di Falco, P., Brighigna, L., 2011. Megasporogenesis and programmed cell death in Tillandsia (Bromeliaceae). Protoplasma 248, 651-662.

Pignatti, S., 1982. Lunaria L. Flora d'Italia, vol. 1. Edagricole, Roma, pp. 421-422.

Reynolds, E.S., 1963. The use of lead citrate at high $\mathrm{pH}$ as an electron-opaque stain for electron microscopy. J. Cell Biol. 17, 208-212.

Spurr, A.R., 1969. A low-viscosity epoxy resin embedding medium for electron microscopy. J. Ultrastruct. Res. 26, 31-36.

Van Caeseele, L., Mills, J.T., Sumner, M.J., Gillespie, R., 1982. Cytological study of palisade development in the seed coat of Candle canola. Can. J. Bot. 60, 2469-2475.

Vaughan, J.G.F.L.S., Whitehouse, J.M., 1971. Seed structure and the taxonomy of the Cruciferae. Bot. J. Linn. Soc. 64, 383-409.

Venier, P., Funes, G., Carrizo Garcìa, C., 2012. Physical dormancy and histological features of seeds of five Acacia species (Fabaceae) from xerophytic forests in central Argentina. Flora 207, 39-46.

Western, T.L., Skinner, D.J., Haughn, G.W., 2000. Differentiation of mucilage secretory cells of the Arabidopsis seed coat. Plant Phys. 122, 345-355.

Windsor, J.B., Vaughan Symonds, V., Mendenhall, J., Lloyd, A.M., 2000. Arabidopsis seed coat development: morphological differentiation of the outer integument. Plant J. 22, 483-493.

Zobel, A.M., 1985. The internode of Sambucus racemosa L. originates from a single cell layer. Ann. Bot. 56, 105-107.

Zobel, A.M., 1986. Localization of phenolic compounds in tannin-secreting cells from Sambucus racemosa L. shoots. Ann. Bot. 57, 801-810.

Zobel, A.M., 1989. Cytoplastic and apoplastic location of phenolic compounds in the covering tissue of the Brassica napus radicle between embryogenesis and germination. Ann. Bot. 64, 149-157.

Please cite this article in press as: Mosti, S., et al., The unusual tegumental tissues of the Lunaria annua (Brassicaceae) seed: A developmental study using light and electron microscopy. Flora (2012), http://dx.doi.org/10.1016/j.flora.2012.09.008 